upgrading, the same month that the TFTR plans to start its own experiments with tritium - the basic fuel for a commercial fusion reactor.

The main purpose of the JET modifications is to study ways of reducing the impact of impurities caused by interaction between the burning plasma and the wall of the tokamak. Such impurities seriously limit the length of ignition; their effects are expected to be reduced by the insertion of a pumped divertor, which traps the impurities by modifying the shape of the magnetic field at the plasma edge and allows them to be removed by a cryopump.

When the divertor studies will be completed by the end of 1994, JET will enter its final stage of full-power operation with deuterium-tritium plasma. Before that happens, however, the spotlight will have been turned back to Princeton's TFTR, where scientists hope to study for the first time the heating effects of alpha particles on the plasma contained by the magnetic field inside the tokamak. Equally important in political terms is the fact that the tritium experiments will allow the TFTR to reach power levels of 5-10 MW, surpassing the 2 megawatts achieved in 1991 by JET using 11-per-cent tritium injected into the deuterium plasma.

The experiments at JET and Princeton will provide results for what is most likely to be the next major goal for the fusion community, namely the construction of the \$6billion International Thermonuclear Experimental Reactor (ITER). Progress on ITER has been slow but steady. The formal agreement setting the framework for cooperation was signed last summer in Washington by the four international partners (the United States, the European Communities, the Russian Federation and Japan). The next twelve months should see a continuation of the design engineering work and the building up of research teams at the three design centres at San Diego in California, Garching in Germany and Naka in Japan (see Nature 360, 615; 1992).

\section{Halfway measures}

Banking on possible delays to ITER, a number of national initiatives have been put forward as intermediate steps. In the United States, the political focus will be on a proposal from Princeton to build a new Tokamak Plasma Experiment (TPX), a $\$ 500$-million project which, if approved, would begin operation around 2003 (see Nature 356, 96; 1992). It would succeed the TFTR, which will be closed in 1994 because of the radioactivity caused by the use of tritium in the forthcoming series of experiments. After winning the backing of the US Department of Energy under the Bush administration, its fate now lies in the hands of President-elect Bill Clinton and his vice-president, $\mathrm{Al}$ Gore.

Across the Pacific, more discreet lobbying efforts are under way to persuade the Japanese government to follow up the

successful operation of its own fusion machine, JT-60, with a new steady-state tokamak. It is also seen as a stepping-stone to ITER. In Europe, as the main political focus shifts from JET to ITER, pressure is also likely to mount for funding for an alternative advanced machine, namely a stellarator, which physicists would like to build at the Institute for Plasma Physics in Garching.

Newspaper headlines in Europe, however, are likely to concentrate on a more pressing question, namely how to handle the consequences for scientists of the eventual closing of JET. The issue is of particular concern to British staff who, unlike colleagues from other European states, work under contract to the British AEA Technology, rather than to Euratom.

\title{
Networks enhance use of computers
}

Scientists can be expected to continue finding new ways to take advantage of improvements in the scope and speed of high-performance computers. As computing power becomes more crucial to national and regional economic security, two areas attracting the most attention are massively parallel processing, in which thousands of individual processors perform millions of tasks simultaneously rather than sequentially, and the linking of highperformance computers to networks.

The European Communities (EC) are being urged to begin a decade-long high-performance computing research programme using public and private funds amounting to ECU1 billion (US $\$ 1.25$ billion) a year. Part of the sales pitch, outlined in an October report by a European Commission panel led by CERN's Carlo Rubbia, is that there exists a "unique window of opportunity" for Europe to invent new hardware and software applications for the latest breed of massively parallel high-speed computers. The current research and development programmes, ESPRIT and RACE, have pushed the technology ahead and produced startup companies, but the report laments that larger companies from outside Europe often are quicker to exploit the markets created by new technologies (as Fujitsu Ltd hopes to do in acquiring the British computer maker ICL).

The name that Japan has given to its high-performance computing initiative - the Real World Computing project reflects an emphasis on applicationsorientated research, as well as a step back from the lofty goals of its less-thansuccessful predecessor, the now cancelled Fifth Generation project on artificial intelligence. Meanwhile, Fujitsu will attempt to move ahead of the pack with what promises to be the fastest supercomputer yet.

In the United States, which leads the world in massively parallel processing and
A report commissioned by the Commission at the prompting of the European Parliament has recommended that British scientists be given the same contractual status as their European colleagues (see Nature 357, 270; 1992). But this will cost money, and implies a long-term commitment that the British government has so far not been willing to make.

The JET council meets in March to discuss its next move. Without a shift in Britain's position, the council is unlikely to be in a position to recommend a solution to the dispute. Union representatives are already warning that such an outcome could lead to a renewal of last summer's strikes. This looming dispute suggests that fusion may generate some heat this year, even if not the type originally intended. David Dickson

semiconductor research, the new Clinton administration is preparing to launch the second phase of a High-Performance Computing and Communications project to provide new supercomputer applications for health care, education and manufacturing. A key component on the project, launched in 1991, is the five-year effort to create a National Research and Educational Network using optical fibre cables to connect universities, major research centres, industry and possibly even homes.

Towards that end, the US Department of Energy and American Telephone and Telegraph $\mathrm{Co}$. are improving the speed of such a network. One test scheduled for this summer will involve researchers using two Cray supercomputers to link 30 computers capable of transmitting 1 billion bits of information. That would be equal to sending 100 novels every second. The speed of the US Internet databank system will also be improved in 1993, from 1.5 million bits per second to a consistent 45 million bits per second, with laboratory tests in the mid-100 million to one-gigabit range.

\section{Greater efficiency}

Research into the field of high-performance computing will continue to focus on making supercomputers faster, but an equal challenge will be to make them work more efficiently. A central goal is rapid transmittal of massive amounts of data in the form of moving video. The supercomputers seem up to the task, but technical problems inhibit networks from carrying such vast amounts of data. Optical fibre network switches so far are unable to detect and correct transmission errors at such high speeds. Regulatory logjams also plague the network in the United States, as telephone companies lack government permission to charge rate tariffs sufficient to cover the costs of transmitting large volumes of high-speed data.

In the realm of parallel processing, 
computer engineers must also grapple with the problem of standardizing computer software in a way that manufacturers and businesses find appealing. One leading option is "high-performance Fortran", which adapts one of the oldest and most widely used computer languages to massively parallel supercomputers.

Another avenue is to combine the best features of parallel and traditional vector supercomputing, which use a much more efficient linear method of calculation. By September, Fujitsu plans to start selling a supercomputer capable of performing at 355 billion operating instructions per second, or gigaflops, that will use a combination of the two technologies and do in a minute what would take 10 days on a typical desktop workstation. Fujitsu claims the machine will be able to use existing software, while also having the performance advantages of parallel processing. Cray also plans to roll out a hybrid system that would allow users to attach parallel processing features to their current supercomputers. And in June, Oak Ridge National Laboratory in Tennessee will begin using an Intel Paragon supercomputer that will operate at a peak of 150 gigaflops.

Further down the line, the Japanese project combines research on massively parallel machines with optical computing, using beams of light rather that electronic impulses to transmit data. The Japanese have urged researchers from around the world to join the project. Although cost-sharing might sound appealing at a time when EC scientists struggle with the uncertainties of a divided Europe and US scientists are weaning themselves from a shrinking defence department research budget, so far few companies have taken Japan up on the offer - another indication of the intense competition in the field.

Michael Mills

\section{Hubble repairs to top active year in space}

The US National Aeronautics and Space Administration (NASA) hopes that 1993 will bring an end to its biggest public relations headache of recent years as space programmes around the world prepare for 12 months of down-to-earth politicking as well as extraterrestial exploration.

In December a seven-member crew, including European astronaut Claude Nicollier, will attempt to rehabilitate the Hubble Space Telescope. In a series of complex space walks, the astronauts will install a set of corrective devices to compensate for flawed optics in the $\$ 1.5$ billion orbiting telescope, launched in 1990. Even with the defect, scientists have been able to carry out a range of research projects, including searching for evidence of black holes in distant galaxies. However, the repair mission is a prerequisite for other such eagerly awaited efforts as measuring the rate of expansion of the Universe.

In April the same shuttle, the Endeavour, will try to retrieve the European Space Agency's Eureca satellite. Placed in orbit this past July, Eureca carries experiments to determine the effects of radiation and weightlessness on such objects suspended outside the satellite as photoelectric cells and plant spores. It is designed to be launched repeatedly after being plucked from orbit and returned to Earth.

In August, NASA's Mars Observer spacecraft is expected to begin orbiting the red planet. Meanwhile, the space agency's Magellan probe of Venus is expected to cease operations in May.

As usual, most new scientific and science-related spacecraft in 1993 will be launched on unmanned expendable rockets.
Geologists, oceanographers and others who events on the Earth's surface will benefit from two new satellites. In September,

France will launch its SPOT-3 remote-sensing spacecraft, replacing the ageing SPOT2 satellite, and next month the US government had planned to launch its Landsat 6 remote-sensing spacecraft to replace its Landsat 4 and Landsat 5 spacecraft, which have exceeded their scheduled lifetimes. But a defect in the spacecraft's solar panels is expected to cause an indefinite delay.

Other significant scientific payloads include the launch in August of NASA's Sea use remote-sensing spacecraft to monitor

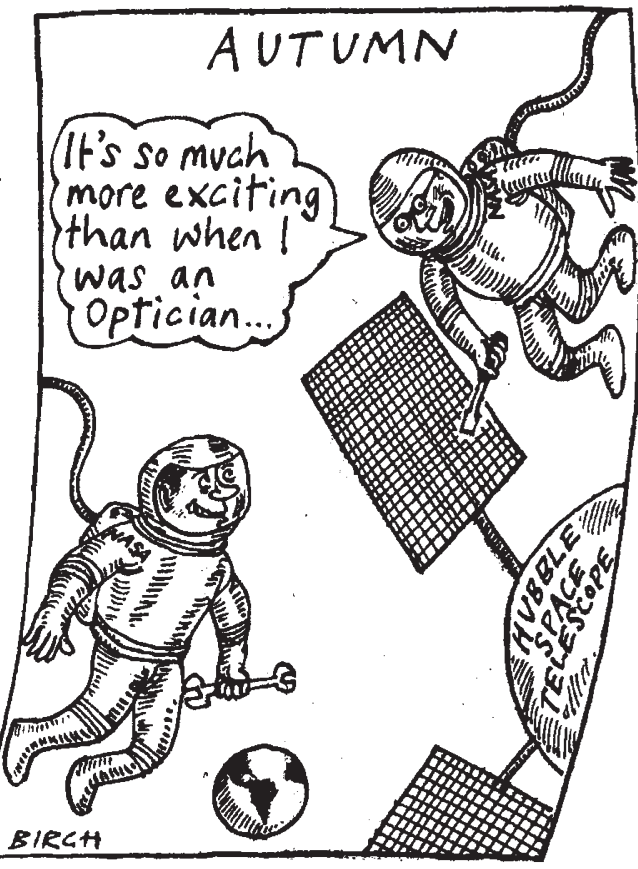

Wide-Field Sensor spacecraft to monitor chlorophyll levels and improve understanding of the global carbon cycle; the launch this month of Brazil's first homemade satellite, to relay environmental data, and next month's launch of Astro-D, Japan's X-ray satellite. The US Defense Department also plans to orbit a scientific spacecraft, known as Alexis, carrying both X-ray telescopes and an experiment to monitor interference with radio transmissions.

Several spacecraft will explore solar physics. NASA's Wind spacecraft, due to be launched next December, will work in concert with Japan's Geotail spacecraft launched in 1991. The Russian space agency's principal scientific launch this year will be a pair of spacecraft to monitor interactions between the solar wind and the Earth's magnetosphere.

Russia also has plans for three manned flights to dock with the Mir space station, including a flight in July featuring a threeweek visit by a French cosmonaut. In November, a Russian cosmonaut is scheduled to fly on a US space shuttle mission, setting the stage for a visit in 1994 by a US astronaut aboard Mir.

However, despite all the activity on launch pads and control rooms around the globe, the most far-reaching developments affecting space may occur in legislative chambers and government offices. In the Commonwealth of Independent States, officials are trying to continue a vibrant space effort in the midst of continuing economic and political turmoil. Compounding the problem is squabbling among the three republics with the greatest interest in space: Russia, which builds most spacecraft and rockets; Kazakhstan, which is the launch and landing site for most missions; and Ukraine, which is home to some manufacturing and telemetry facilities. Simultaneously, the member countries of the European Space Agency are attempting to forge closer relations with the massive post-Soviet space apparatus in an era of tight budgets on both sides.

In the United States, the Clinton-Gore administration and a substantially new Congress are expected to rekindle longstanding political battles relating to space. For example, as a US senator, Vice President-elect $\mathrm{Al}$ Gore badgered reluctant Pentagon officials into approving access for environmental researchers to previously secret measurements made by US spy satellites. As chairman of the National Space Council, Gore may be able to make the military respond more quickly.

And in the US Congress, the planned space station Freedom is likely to be the most contentious issue in space policy. During the presidential campaign, Clinton and Gore voiced support for Freedom. But it is far from clear that Congress, faced with stiff competition for a tight budget, will hold to past agreements to build the $\$ 37$-billion orbiting platform.

Vincent Kiernan 